\title{
An Improvised Online Quiz Conduction Mechanism Through Quiz-O-Pedia
}

\author{
Ms. Supriya A. Chaudhari \\ Diploma Student, \\ Computer Engineering Department \\ MGM's polytechnic, Aurangabad (MS), India \\ Ms. Samruddhi S. Baviskar \\ Diploma Student, \\ Computer Engineering Department \\ MGM's polytechnic, Aurangabad (MS), India \\ Ms. Pooja N. Yewale \\ Diploma Student, \\ Computer Engineering Department \\ MGM's polytechnic, Aurangabad (MS), India
}

\author{
Ms. Sayli B. Wagh \\ Diploma Student, \\ Computer Engineering Department \\ MGM's polytechnic, Aurangabad (MS), India
}

\author{
Ms. Disha J. Kolte \\ Diploma Student, \\ Computer Engineering Department \\ MGM's polytechnic, Aurangabad (MS), India
}

\author{
Prof. Poonam V. Polshetwar \\ Lecturer \\ Computer Engineering Department \\ MGM's polytechnic, Aurangabad (MS), India
}

\begin{abstract}
The computer network and information technology area is developing rapidly in recent days. It is making vital changes to human beings in the fields of study, work and the way of life. Due to Corona pandemic situation, online examinations are becoming important method of accessing and evaluating the success potential in students. The proposed system is developed to overcome the debugs of existing manual testing system to survive in this pandemic problem. The primary goal of the proposed system is to effectively assess the student performance thoroughly with the help of completely automated system that not only helps to save a lot of time but also gives quick outcomes. The purpose of the online examination system is to companies or institutions to conduct various examinations for any number of candidates at a time, in a paperless manner.
\end{abstract}

It helps to save the time consumption and amount of efforts required to conduct the variety of examinations and their evaluation process. It also provides a facility to add tests for particular subject, to add a new subject in efficient and flexible way which allows performing paperless work. The online examination system is also useful to maintain the safety factor which is necessary to survive in Corona pandemic situation without disturbing educational life. This online examination system also makes the user easy to collect the information about aptitude test which is important for placement and higher studies.

\section{Keywords-Online quiz; automation;Restful API;}

\section{INTRODUCTION}

The quiz-o-pedia is a web application used to take online test in an efficient manner, it saves the time as checking is paperless because everything is online, so from giving test to displaying result everything is online so its environment friendly.

The main objective of this online quiz portal is to let the user know about the depth of knowledge. It gives fast results as compare to manual system. User can register, login and give the test and can see the result of test as well. Without any cheating result is displayed and it is trust worthy. This website is useful for beginners and also for experts i.e. new comer can solve easily test and professionals can give hard tests. Its free of cost, education should be spread free of cost.[4]

\section{OBJECTIVES}

\section{A. Saves paper}

Through the proposed system, there is no need to print the test exam papers and evaluation result for students and hand them out. In this way proposed work saves paper which in case saves the trees.

\section{B. Reduces the time}

This work can setup an exam in such a way that it wills auto-grade itself. If the user only use multiple choice questions then there is no need check an exam again. The online exam system will take care of this hassle. This system is completely automated.

The dealing out of the exam does not take any time. Just upload the email addresses of students and send them an invite. And after the exam students will get their result instantly.

\section{Platform independent}

Because of this restful API we can perform test on any platform such as MAC (Macintosh), Windows, Android, LINUX etc. Admin or faculty can check progress on a single click. This enables to track the report and progress of a candidate on a fingertip.

The major feature which adds up to the net examination is expandable over a larger region. Technology made it very easy to use the online examination system.

\section{Data Security}

A bigger question bank with a lot of questions can be produced through "Quiz-O-Pedia" so that each student can have a random selection from that question bank. 


\section{LITERATURE SURVEY}

The work on testing and examinations has focused on freetext entry style answer (Du Ploov 1992). The second experiment, conducted early in 1999, enabled students to want a 'mock exam' accessed via an online page as a component of their revision. The experiment was designed to check out the technical feasibility of offering the seventeen unsupervised home examination. Students accessed the paper via an online site and submitted their answers in a very similar way. the scholars keyed their answers into a regular application, the results of which were encrypted and returned via a secure website by the invigilator at the most effective at the best of the examination period (Breithaupt et al 2005, Carswell et al 1999).[1]

Ping Guo et al (2008) proposed that the web examination system (OES) is also divided into two models; they're BrowserServer model and Client-Server model (Buchanan 1999, Liu et al 2004), the elemental functions of them remained the identical. An OES contains a series of functions including intelligent auto-generating test sheet (Zhang and Zhan 2001), tracking and recording of the strategy of candidates' answering, intelligent marking and thus the statistical analysis of students' grades so on. Moe Aye and Mie Thet Thwin 2008 aimed to model an agent-based system, able to replace the prevailing paper-based examination system. this method aims to map closely to planet online examination scenarios and to satisfy the lacks of this systems.[2][5]

\section{SYSTEM ARCHITECTURE}

A Unified Modeling Language, UML use case diagram is the primary form of system/software requirements for a new software program underdeveloped. Use cases specify the expected behavior (what), and not the exact method of making it happen (how). Use cases once specified can be denoted both textual and visual representation (i.e. use case diagram).

A key concept of use case modeling is that it helps us design a system from the end user's perspective. It is an effective technique for communicating system behavior in the user's terms by specifying all externally visible system behavior. A use case diagram is usually simple. Figure 4.1 UML Diagram

- It only summarizes some of the relationships between use cases, actors, and systems.

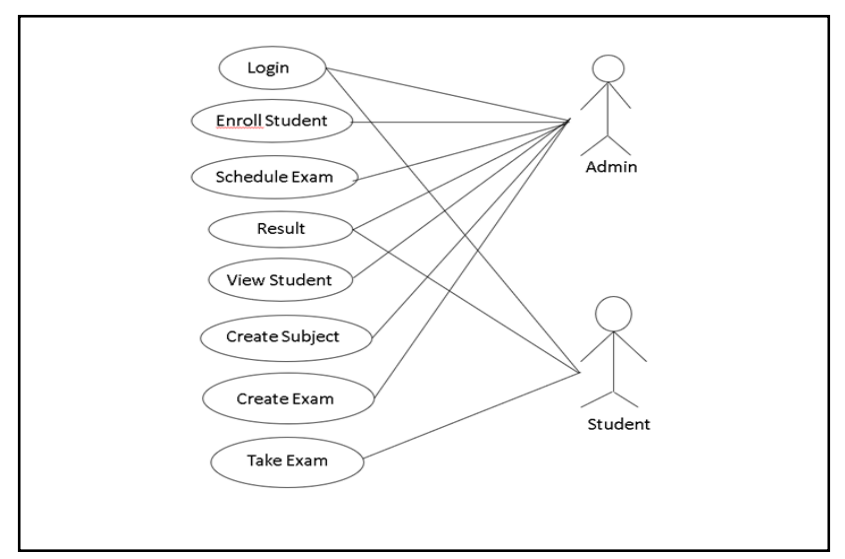

Fig 4.1 UML Diagram

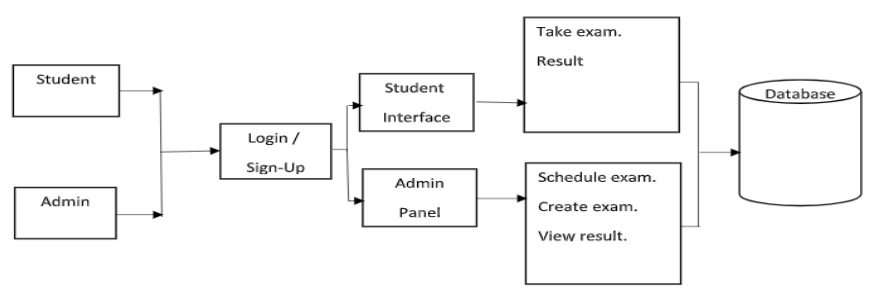

Figure 4.2 System Architecture

\section{A. Modules}

The implementation of online examination system i.e. "Quiz-O-Pedia" is based on latest trends that are used in now days for web page designing and development. After examining the technical and economical feasibility of online examination system, perquisites for proposed system are collected. These requirements are used to divide the entire online examination system in to two sub problem statements. One of the problem statements is used to develop admin access and second problem statement is used to work for student access. In this proposed work, JavaScript is used as scripting language and XAMPP server is used to store database regarding to admin, student, test and result along with JQuery and Restful API.[3][6] The proposed work depend on two important modules admin module and student module.[2]

\section{1) Admin module:}

Admin consist of admin sign in page which in scripted using html, css and admin dashboard where admin/teacher can view student's result and add/create subjects as many as admin/teacher wants and can add/create test as many as admin/teacher wants and also questions. Admin/teacher can also delete a particular test and subject. Admin/Teacher can create/add test of particular subject with no limit of adding question. Admin/teacher can also add timer to test/exam hence when time limit gets over it terminates the quiz/exam and shows result of test.

\section{2) Student Module:}

Here Student module consist of login / sign in page where student have to enter username and password, if student is not register they have to signup registration form with all necessary and valid details. After login web will directed to student dashboard where student can see there test result ,subjects and attempted and non attempted test. Here when exam or test starts it should be completed in given time duration when time limits get over it automatically exam gets terminated.

\section{SCREENSHOTS}

Snapshot 5.1 is admin dashboard or home page after login admin is directed to admin dashboard. The left black dashboard displays score or result of students. The center dashboard show total number of subjects created or added and total number of test/exams created/added also total number of students registered. The dashboard below it Subjects on left side shows details of all subjects and tests/exams created. 


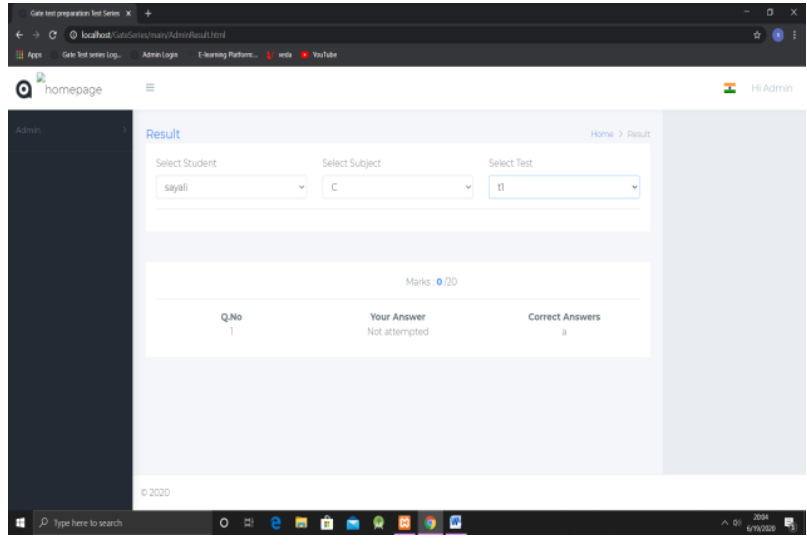

Snapshot 5.1 Admoin Dashboard

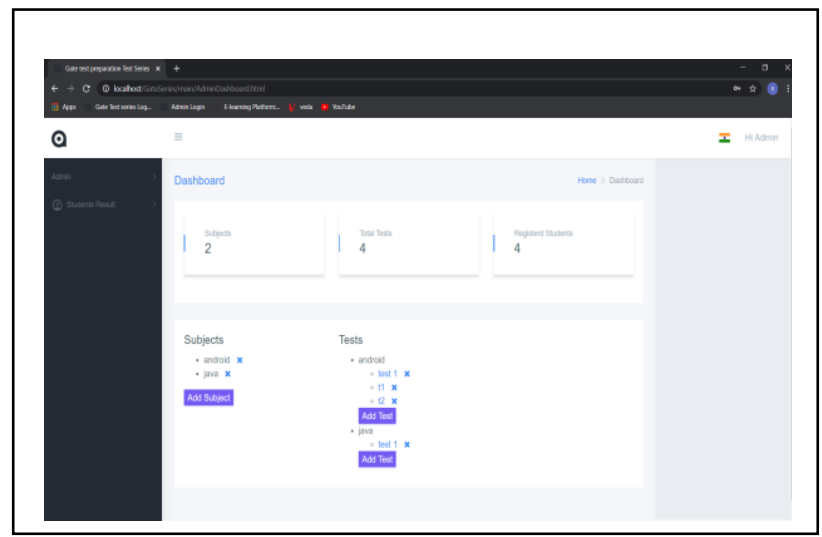

Snapshot 5.2 Result dashboard

The result dashboard of admin module we have provided features like we can search and check a particular student's result if register

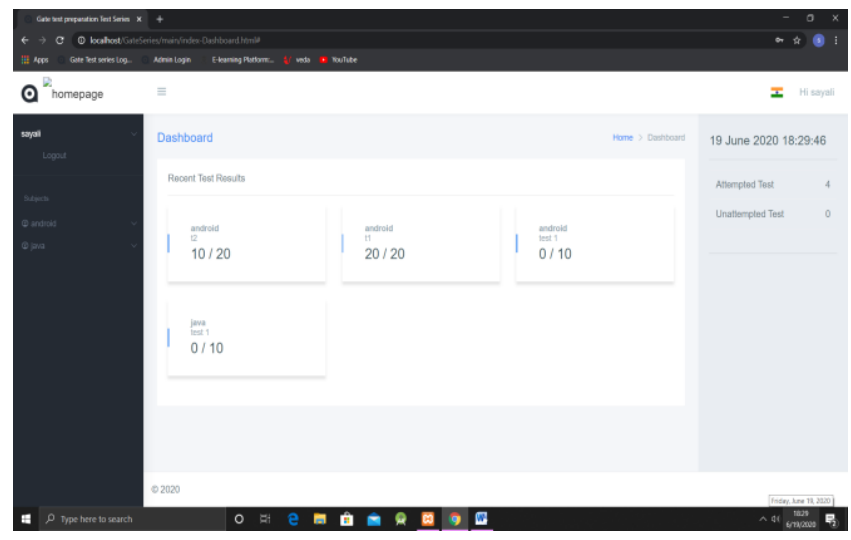

Snapshot 5.3 Student Dashboard

Snapshot 5.3 student dashboard after student gets logged in web directs it to homepage dashboard. Here on left side of dashboard shows student name, logout option and list of subjects. And the middle white dashboard shows all recent test's score or result and on right side of dashboard it shows all attempted and unattempted test.

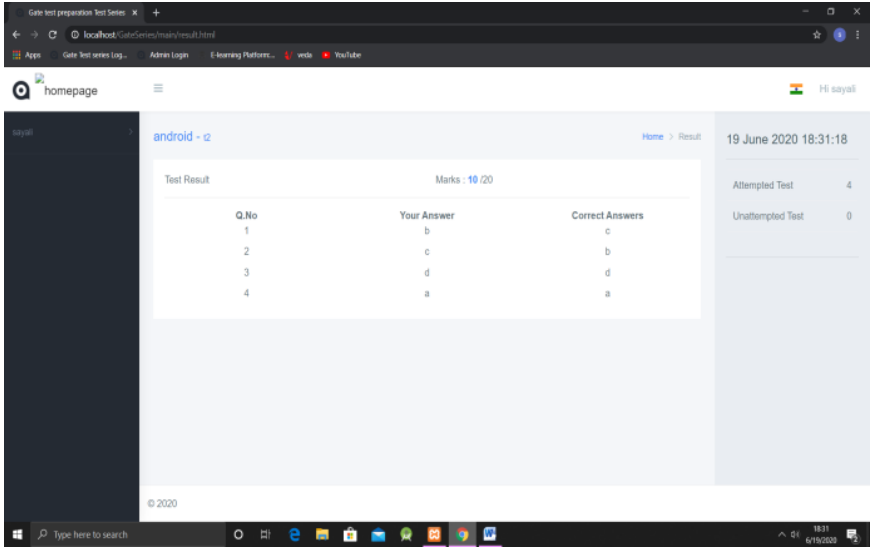

Snapshot 5.4 Result dash board in student module

Snapshot 5.4 shows result dashboard in student module to check score/result of particular test.

\section{PROPOSED WORK}

Proposed system provides a platform for a set of common examination for the college platform by providing well organized tests. It also has a great reference value for other colleges and universities.

As in state of affairs of pandemic, online examination is very major application and it plays a crucial role in online teaching. Proposed work has made it easy for student to attempt exam or test from anywhere with help of any decent device and internet. And for teacher it's easy to check paper, provide question bank, notes on topics, and keep up to date.

This system can conduct examination world wide so that education can spread everywhere and many students and teachers will get more scope..

\section{CONCLUSION}

This Web Application provides facility to require online examination worldwide. It save the time because it allows number of scholars to convey the exam at a time and displays the results of the exam when exam is completed, so no have to sit up for the result. it's automatically generated by the server.

Administrator \&Coordinator includes a privilege to form, modify and delete the test papers and its particular questions. User can register to exam system, login and provides the exam together with his specific id, and might see the results furthermore. the most purpose of our project is to develop an application that gives new aspects of learning and improving knowledge in educational area. Most of the available apps are entertainment-based, which mostly don't contribute to the tutorial enhancement of the scholars.

The theme of our quiz is to supply user to practice for subjective tests conducted, so during this app we specialize in engineering field. This quiz is helpful for the preparation of any of the computer-related test. This quiz o pedia includes some main modules, namely teacher dashboard and also the student dashboard. The teacher module contain add test sub module here teacher can add the test alternatively they'll delete the test ,up to 30 questions teacher can add the question in test including marks weight age which is completely rely upon the teacher. Also teacher can get the progress of scholars also. 
within the other hand student module contain start test, select subject and also student can provides a feedback

\section{ACKNOWLEDGMENT}

We would like to express our gratitude towards guide Prof. P. V. Polshetwar for the useful comments, remarks and for giving her valuable guidance and inspiration throughout the learning process of this report.

Furthermore, we would like to thank our HOD (Prof. P.D. Jadhav) for making available all the facilities for the successful completion of this work and other staff members of Computer Engineering Department for their valuable help.

It is with humble gratitude \& sense of indebtedness, we thank my respected and esteemed Principal (Dr. B. M. Patil) for his valuable guidance, suggestion and constant support which lead towards successful completion of this work.

\section{REFERENCES}

[1] A web services based online training and exam system(Hua Pang, Shu Yang , LiyingBian)Published i:nWireless Communications, Networking and Mobile Computing, 2008. WiCOM '08. 4th International.

[2] Design and implementation of an online self-training system for the Computer System Platform course. Published in: Advanced Computational Intelligence (ICACI), 2012 IEEE Fifth International Conference on.

[3] Yuan, Z. Zhang, L and Zhang, G. (2003) A Novel Web-Based Examination System For Computer Science Education. 33rd ASEE/IEEE Frontiers in Education Conference.S3f-7-s3f-10.

[4] https://searchapparchitecture.techtarget.com/definition/RESTful-API

[5] https://www.edudose.com/gk/

[6] https://www.w3schools.com/php/DEFAULT.asp 